\title{
«We don't eat people»: la nueva ética del sistema caníbal propuesta por la narrativa audiovisual postapocalíptica del siglo XXI
}

\author{
«We Don't Eat People»: How the Post-apocalyptic \\ Cinema of the 21st Century Teach Us the New Ethics \\ of the Cannibalistic System
}

\author{
ALFONSO M. RODRÍGUEZ DE AUSTRIA GIMÉNEZ DE ARAGÓN*
}

\begin{abstract}
Resumen: El género de películas de catástrofes está estrechamente relacionado con los tiempos de crisis económica y social. Fue a partir de la «crisis del petróleo» de comienzos de los años setenta cuando el género se consolidó. Estas películas tenían la función de servir de catarsis y mostrar a la población lo afortunada que era de no sufrir una desgracia peor que la crisis. La crisis global que emergió en el año 2005 ha traído consigo una nueva acumulación de películas centradas en la vida tras el apocalipsis. La función de estas películas no es servir de catarsis, sino proponernos el abandono de nuestros viejos esquemas morales en beneficio de una moral de supervivencia más acorde con la crisis global y perpetua que padeceremos. Palabras clave: moral, ética, cine, apocalipsis, crisis, canibalismo.
\end{abstract}

\begin{abstract}
The disaster movie genre is closely related to the times of economic and social crisis. The consolidation of the genre came from the «oil crisis» in the early seventies. These films worked as a catharsis and showed real people how lucky they were because of suffering just an economic crisis and not something worse. The global crisis that emerged in 2005 has brought a new accumulation of films focusing on how will be life after the Apocalypse. These films don't work as a catharsis, instead they are proposing the withdrawal of our old morals schemes in favor of a new ethics of survival. An ethics more in line with the global and perpetual crisis that we are going to suffer from now on.
\end{abstract}

Keywords: Moral, Ethics, Cinema, Apocalypse, Crisis, Cannibalism.

Los primeros caníbales cinematográficos de los que las personas occidentales del siglo $\mathrm{XX}$ podemos tener recuerdos son, probablemente, aquellas maravillosas tribus africanas que descuartizaban, entre palmeras, los cuerpos de los incautos exploradores blancos al grito de yu-yu, yu-yu (que tanto se repitió en los patios de colegios españoles de la década de 1980), y luego los cocinaban en enormes marmitas al fuego.

Fecha de recepción: 08/06/2016. Fecha de aceptación: 17/07/2016.

* Universidad Centroamericana de Nicaragua, profesor de postgrado y formación continua. alfonso.m@ rodriguezdeaustria.es Líneas de investigación; retórica, ideología, propaganda, lenguaje audiovisual, comunicación política. «Aristóteles en Hollywood: poética y retórica en la narrativa audiovisual.» FOTOCINEMA, Revista científica de cine y fotografía, $\mathrm{N}^{\circ}$ 11, 2015. «El código de producción de Hollywood (1930-1966): censura, marcos (frames) y hegemonía.» ZER, Vol 20, Nº 39, 2015. 
Un segundo grupo de caníbales maravillosos emergió en la década de los 60 en la forma de muertos vivientes, aunque antes de convertirse en los obsesivos devoradores de cerebros y carne humana que conocemos actualmente, los zombis pasaron por un periodo de hibridismo con los vampiros gracias a la novela de Richard Matheson I am Legend, de 1954, llevada a la pantalla en 1964 por Ubaldo Ragona y Sidney Salkow con el título The Last Man on Earth y Vincent Price de protagonista, y algunos años después por Boris Sagal con el título The Omega Man, 1971, esta vez protagonizada por Charlton Heston.

Entre ambos títulos, George A. Romero había dirigido y estrenado Night of the Living Dead, 1968, con la cual sentó las bases del género, y que en la segunda década del siglo XXI están siendo superadas. La principal característica que poseen los zombis desde entonces es que se guían por el instinto voraz y compulsivo de comer humana.

En el siglo XXI los zombis, y podemos decirlo con todas las letras, han vuelto a la vida cultural y económica convirtiéndose al mainstream, emergiendo de las profundidades de la Series B y Z y el cine de culto. 28 Days Later (Danny Boyle, 2002), 28 Weeks Later, (Juan Carlos Fresnadillo, 2007), la saga Residet Evil (2002, 2004, 2007, 2010, 2012 у 2016), Zombieland (Ruben Fleischer, 2009), World War Z (Marc Forster, 2013), o las series de televisión The Walking Dead (2010-...), Z Nation (2014_...), iZombie (2015-...) o Fear The Walking Dead (2015-...) son algunos de las producciones de mayor éxito.

Pero aún quedaba por llegar un tercer grupo de caníbales, invocado tal vez por la máxima del mercado audiovisual de ofrecer a los sistemas nerviosos de los consumidores experiencias siempre novedosas e impactantes, las personas del primer mundo que comen personas. No nos referimos a psicópatas individuales aficionados al canibalismo, como Hannibal Lecter (1991, 2001, 2002) o Carlos, el sastre de Granada (Caníbal, Manuel Martín Cuenca, 2013), sino a grupos o tribus que ejercen su práctica de forma compartida y comunitaria.

El marco narrativo en que surgen estos grupos caníbales es el mundo, o lo que queda del mundo, tras el apocalipsis nuclear, viral, zombi o ecológico. El contexto natural en que florecen este tipo de prácticas es la escasez total de recursos, incluyendo la comida y el agua. El contexto social es de desaparición absoluta de la civilización organizada, más allá del grupo surgido de encuentros casuales y cohesionado por un objetivo común, o de la tribu consolidada por mentalidades y prácticas afines.

Las narrativas postapocalípticas, como la ciencia ficción y los géneros fantasiosos en general, pueden y suelen contener un núcleo de realismo revestido de situaciones «límite». La descripción de utopías, distopías y mundos alternativos, tiene una larga tradición crítica sobre la realidad, bien porque la crítica directa puede ser objeto de censura, bien porque la libertad creativa del género permite el acercamiento metafórico a aspectos de la realidad que era difícil describir con un lenguaje político o científico. Las utopías/distopías políticas de Platón, Tomás Moro, Tommaso Campanella o Francis Bacon, las literarias de Jonathan Swift, Samuel Butler, H. G. Wells, George Orwell o Aldous Huxley, más una ingente cantidad de títulos cinematográficos, han usado esta forma de denunciar los males de la sociedad y/o ofrecer alternativas a la misma. El género cinematográfico de ciencia ficción estadounidense de los años 50 siguió en general una línea diferente. Plagado monstruos de tiempos remotos y extraterrestres invasores, respondía en cierta medida a la ansiedad social ante la amenaza del terror rojo y la nada desechable posibilidad de una 
guerra nuclear. Una ansiedad, por supuesto, favorecida y propagada por los insistentes conglomerados económicos del país como mecanismo de control social. Algo por cierto denunciado por el primer tipo de utopías/distopías a las que hemos hecho referencia.

El género o subgénero cinematográfico postapocalíptico del siglo XXI está respondiendo a un tipo de ansiedades políticas y sociales más acordes con el nuevo escenario mundial inaugurado por la crisis global y la guerra permanente contra el terror. La guerra fría, el terror rojo y el peligro nuclear han dado paso a la guerra de civilizaciones, el terrorismo internacional y el colapso ambiental. El trasfondo es el mismo, sólo que en un contexto más extremo, en tanto que menos evitable que la guerra nuclear: el control sobre unos recursos naturales cada vez más escasos. Lo que antes era el enfrentamiento entre dos modelos antagónicos de producción económica y social, se ha convertido ahora en una reorganización interna del modelo hegemónico. El triunfo del capitalismo sobre el denominado bloque comunista, la desaparición del supuesto enemigo mortal, le permite ahora al sistema deshacerse de sus excrecencias, toda vez que estos miles de millones de personas sobrantes (tal vez dos, tal vez tres, tal vez más) no tienen ya un modelo alternativo al que acudir y con el cual amenazar al capitalismo. Ya no asustan al establishment, ya no hace falta siquiera guardar las apariencias, como comprobamos en la segunda década del siglo XXI gracias a la reacción contra la primavera árabe, la guerra en Siria y en el Oriente Medio, y la denominada crisis de los refugiados.

Sabemos gracias al trabajo de Naomi Klein (La doctrina del Shock. El auge del capitalismo del desastre, 2009) que las políticas predatorias del capitalismo del desastre son aplicadas más fácilmente cuando la población se encuentra en estado de shock. El consejo del economista ultraliberal Milton Friedman era aprovechar los desastres, provocados o no, para imponer las políticas corporativistas y acabar definitivamente con las injerencias reguladoras del Estado en la economía. Es decir, privatizar para las grandes corporaciones lo que quedase de propiedad pública y/o comunal.

El mundo postapocalíptico es el escenario perfecto para implementar las políticas corporativistas más extremas. Es el desastre total, el shock permanente, la desaparición del Estado regulador, del antiguo orden social. En la literatura ciberpunk son las megacorporaciones y el individualismo más extremo quienes dictan las nuevas normas: la competición directa y sin injerencias por los nichos económicos (Market Forces, Richard Morgan, 2004). En la narrativa audiovisual postapocalíptica del presente siglo, copada por la extrema derecha y la atroz corriente ideológica del mal llamado anarcocapitalismo, asistimos a la emergencia de una nueva sociedad tribal en la que los grupos compiten entre sí por los escasos recursos, en igualdad de condiciones, en libertad.

La debacle socionatural lleva aparejada la suspensión indefinida de cualquier tipo de moral en beneficio de la propia supervivencia, y a veces, sólo a veces, de la supervivencia del grupo. De hecho, como veremos, cualquier tipo de actitud moral o piadosa con respecto a los semejantes es considerada en estas narrativas como una rémora de tiempos mejores, en los que uno podía detenerse a pensar en los demás. La moral tradicional, de cooperación y amor al prójimo, es sistemáticamente castigada. La piedad es redefinida como debilidad y conlleva la muerte. La empatía con miembros externos al grupo no sirve más que para hacer peligrar la supervivencia del mismo, es un craso y absoluto error.

La suspensión de la moral que se representa en este tipo de narrativas obedece a una política cultural muy clara, y determinada por los grupos conservadores hegemónicos, como 
la corriente ultraliberal. El nuevo escenario de crisis global que se nos presenta, de colapso ecológico, de migraciones masivas, de escasez y apropiación violenta y directa de los recursos por parte de los más fuertes, requiere serias transformaciones sociales y mentales si queremos seguir siendo el primer mundo y seguir disfrutando de nuestros privilegios.

Las políticas de extracción, explotación y acumulación capitalistas, que están conduciendo al colapso humano y natural del planeta, que devoran los cuerpos y mentes de las personas en las cadenas de producción y consumo materiales e inmateriales, encuentran en su avance definitivo un último escollo, una última frontera que les impide imponerse de forma total: la moral, la bondad, la cooperación, la empatía, la mejor parte de la naturaleza humana.

Un sistema caníbal necesita una ética caníbal, no una ética de amor y respeto universal. Necesita una ética en la que el círculo de amor y respeto quede reducido a la familia nuclear, y más aún, reducido únicamente a la propia persona. Necesita una ética de individualismo extremo, del «con nosotros o contra nosotros», del conmigo o contra mí. Una ética de la desconfianza de lo distinto, de lo otro, que haga sentir la mera presencia de alguien desconocido como una amenaza. Una ética de la supervivencia, del «sólo los fuertes sobreviven», como reza el lema de la película X-Men. Apocalypse (Bryan Singer, 2016). La ética de Trasímaco y Calicles en un contexto de supervivencia debido a la escasez. En resumen, la ética de la falta de ética.

Es preciso hacer tabla rasa, olvidarse de los Derechos Humanos. Es preciso que nos acostumbremos al sufrimiento ajeno porque durante los años que llegan lo presenciaremos como nunca antes, de forma generalizada y continua, como el estado natural de las cosas. Cuando queda poco que repartir, sólo los fuertes sobreviven.

El ala ultra del mainstream hollywoodiense se ha puesto manos a la obra en la liquidación de la moral de la solidaridad, imbuyendo sus productos culturales con ejemplos de la patente contraindicación de las actitudes solidarias para la propia supervivencia en el sobrepoblado mundo del siglo XXI. El resquicio por el que los contadores de cuentos audiovisuales llevan a cabo la transvaloración de los valores tradicionales, aleccionados por un poder cuyo control sobre los poetas dejaría atónito a Platón, es una máxima moral formulada en el código de censura de la industria de Hollywood en 1934, y que todas las productoras acataron sin rechistar: Había que dejar muy claro al público espectador que «evil is wrong and good is right». (Ver Rodríguez de Austria, 2015).

Una afirmación como ésta es sintomática de la relevancia secundaria que le daba y le da el poder político estadounidense a la idea de bien: lo correcto (right) es la medida de lo bueno (good), y no al revés, como opinaron Sócrates y Platón, y tras ellos la ética judeocristiana. La afirmación no es reversible, considerar que el bien es lo correcto no es lo mismo que considerar que lo correcto es el bien. El segundo polo de cada frase es el dominante, la vara de medir del primero, y hacia lo que es deseable tender. En el primer caso, hacer lo correcto es más importante que hacer el bien, mientras que en el segundo es al contrario. La afirmación sirve también para distinguir el alcance de cada concepto: si decimos que lo bueno es lo correcto asumimos que el conjunto de lo correcto es distinto del de lo bueno. Invocamos así la existencia de acciones no buenas que entran dentro del conjunto de lo correcto, como las neutras o los «males necesarios». Y de forma complementaria, deben existir entonces acciones bondadosas que entran dentro del conjunto de lo erróneo, equivocado o incorrecto (wrong). 
Esta perspectiva moral está fundamentada en el intuicionismo ético, una corriente de origen británico poco extendida en el resto del continente, más apegado a la herencia moral platónica y las tradiciones grecorromana y judeocristiana. Tal vez texto culmen del intuicionismo ético sea The Right and the Good, de David Ross, publicado en 1930. Entre otras cosas, como el individualismo, la perspectiva intuicionista de la moral facilita la invocación de la preeminencia de la acción correcta sobre la acción bondadosa, algo que supone un gran alivio (incluso una necesidad) en sociedades que ejercen el dominio sobre otras, así como en aquellas en las que la pena de muerte (como ejemplo de acción límite en el terreno moral) es una práctica legal. Sobre el ejemplo concreto de la pena de muerte, pocas personas, ni siquiera las de mentalidad más conservadora (y menos si son religiosas), admitirían que ejecutar a un asesino, en definitiva matar a otra persona, es un acto bondadoso. Sin embargo, no tendrían reparos en sostener que, sin ser bueno, es lo mejor, es decir, lo correcto.

Desde un punto de vista más general, los beneficios para la política del intuicionismo ético son también considerables. El poder político puede encontrar en las tesis intuicionistas la justificación de sus actos malvados, de los males necesarios que se ve obligado a ejecutar, con la finalidad (supuesta o real) de proteger y asegurar la supervivencia de la sociedad que le ha encargado esta tarea. Las críticas negativas a la realpolitik desde el punto de vista moral quedan así conjuradas, de una forma mucho más sencilla y veraz que las más complejas elucubraciones sobre la necesidad de cometer maldades para lograr un bien superior a las que se ven abocadas las éticas que no distinguen entre lo bueno y lo correcto. El intuicionismo ético puede ejercer entonces de poder intelectual sancionador de acciones y prácticas malvadas pero necesarias, correctas, salvando la brecha señalada por Maquiavelo entre la moral y la política.

Es sobre la base de esta perspectiva moral, y enmarcada en la crisis global (económica, social y ecológica) que está viviendo el planeta, en la que se apoya el neoconservadurismo estadounidense para lanzar la citada campaña de lo que podríamos llamar una nueva transvaloración de los valores, en el sentido inverso a la denunciada por Friedrich Nietzsche. La punta de lanza de la campaña parece ser la ficción postapocalíptica, sin duda el mejor contexto para describir la situación extrema a la que se verá abocada la humanidad y el planeta en los próximos decenios, cuando el agotamiento de recursos como el carbón, el petróleo o el agua junto con los efectos del vuelco climático sean hechos consumados. Estas narrativas representan en gran medida el «estado de excepción» definitivo, en el cual queda suspendida la normativa moral acostumbrada, y rigen nuevas leyes cuyo objetivo es la supervivencia de la (nuestra) sociedad.

El núcleo de la transvaloración, de la puesta bocabajo de los valores originales, se cifra en la invocación de lo correcto como valor supremo, por encima del resto de consideraciones morales. Sólo así es posible y deseable llevar a cabo acciones consideradas como malas según las tradiciones morales y religiosas más extendidas. Por ejemplo, negar ayuda al necesitado contradice generalmente los mandatos de estas tradiciones, pero en tiempos de extrema dureza, de acusada crisis global, de escasez de recursos, la supervivencia de la propia persona es la norma básica a seguir, desechando como incorrectas las acciones guiadas por la natural solidaridad de la especie humana. Como veremos, este ejemplo, propuesto a nivel individual, se aplica también a la supervivencia de la propia sociedad. Y así, el acto político-militar (es decir, grupal) de monopolizar la propiedad sobre los recursos es sancionado por la nueva moral como el acto idóneo y correcto, justo y necesario, para la supervivencia de la sociedad. 
Tal vez el mejor ejemplo de esta liquidación de la ética tradicional, de esta campaña para aleccionar a los habitantes del primer mundo sobre las ideas correctas en esta situación de crisis perpetua, sea la película The Road (John Hillcoat, 2009), por su insistencia en el debate moral mantenido por los dos protagonistas, padre (Viggo Mortensen) e hijo preadolescente. En efecto, el chico está obsesionado con la idea de bondad, e insistentemente pregunta al padre si realmente son ellos «los buenos», ya que observa en su progenitor unas pautas de comportamiento que no se adecuan a lo que había aprendido de la vida antes del cataclismo. El personaje del niño representa el último baluarte de la moral, y en una ocasión convence a su padre de que no mate a un hombre que les ha robado todas sus posesiones, dejándole en cambio algo de comida. En la escena siguiente la pareja es atacada por un desconocido de similares características que al que han perdonado (también es negro, de hecho son los únicos personajes negros individualizados de la película), que sin mediar palabra hiere al padre en la pierna. Que una situación suceda a la otra no es casual. La idea que quiere propagarse es que la segunda es consecuencia de la primera. El hecho de perdonar la vida a un rival por los recursos, a un criminal, a un enemigo, sólo trae consecuencias negativas, porque el rival carece absolutamente de escrúpulos. La solidaridad extragrupal del joven protagonista es castigada por un ataque vil y traicionero.

Al año siguiente llegó a las pantallas The Book of Eli (Hughes Brothers, 2010), una película cercana a las tesis teocon o teoconservadoras. El protagonista (Denzel Washington), de nombre Eli («Dios» en hebreo) conserva el único ejemplar de la Biblia que queda en el planeta, y se dirige con él hacia el último reducto de civilización organizada (militarizada). En su camino tiene que enfrentarse al malvado Carnegie (Gary Oldman), una especie de encarnación demoníaca que intenta destruir el libro porque, según su razonamiento, si las personas recuperan la esperanza gracias al contenido del libro, él perderá su poder sobre ellas. Al comienzo de la película veremos cómo Eli, que al final se revela como una especie de ángel custodio, niega su auxilio a una familia que está a punto de ser violada, asesinada y devorada por una tribu caníbal. El bondadoso Eli, que poco después compartirá su escasa comida con un escuálido ratón, sigue su camino y abandona a la familia, intentando convencerse a sí mismo de que es lo mejor gracias a la repetición mántrica de una frase. ¿La frase? No, no es «no puedo hacer nada por salvarles, no puedo hacer nada por salvarles...». La frase es «no es asunto mío, no es asunto mío...».

Volveremos a encontrar situaciones casi calcadas en otras dos ocasiones. En la primera, la llamada de auxilio proviene de una mujer cuya pierna está supuestamente atrapada, y Eli descubre fácilmente que es una trampa, a pesar de lo cual se enfrenta a los malhechores y los liquida con sus superiores dotes para la lucha. En la segunda ocasión, la misma mujer y el mismo truco, sólo que esta vez la incauta es otra mujer que sí cae en la trampa, a pesar de que la malhechora siente solidaridad intragénero y advierte a la benefactora de que debe huir porque todo es una treta. Tarde, por supuesto, así que Eli debe intervenir, esta vez sí, para salvar a su joven e inocente compañera, de la inminente violación grupal.

La lección que extraemos de la película es fácil: no hay lugar para la solidaridad en este mundo en el que hasta la comida escasea, y en el que las personas se unen en tribus para comerse a los externos a la misma, y para no ser comidos por ellos. El mantra «no es asunto mío» es demoledor desde los puntos de vista moral y político. No es que yo solo no tenga el poder suficiente para combatir el mal, y por tanto que exista la salida de conectar 
con otras personas del mismo pensamiento y así acrecentar el poder del bien, es que no es asunto mío, y basta. La individualidad más absoluta, la disgregación social, es la condición previa a la propagación de la insolidaridad.

Seguimos con los ejemplos. En el undécimo capítulo de la segunda temporada de The Walking Dead (2010-...) asistimos a un intenso debate moral entre los miembros del grupo de supervivientes liderados por el expolicía Rick Grimes (Andrew Lincoln). Pues bien, el único personaje que se posiciona en contra de la pena de muerte, Dale Horvath (Jeffrey DeMunn), muere al final del capítulo a consecuencia de un acto de debilidad de otro miembro del grupo a la hora de ejecutar a un zombi (o «caminante»). La indecisión y estupidez de Carl Grimes, un chico que juega a ser mayor apuntando sin disparar a un zombi a atrapado en el barro, provoca que éste ataque y mate al viejo Dale en un momento de confusión. Aunque la situación y el contexto merecen un análisis más detallado, nos contentamos aquí con señalar que, de nuevo, la mínima concesión a un no-miembro del grupo, un rival, es castigada con nefastas consecuencias ${ }^{1}$.

Un par de años después para los espectadores de la serie, suponemos que unos meses en la cronología interna, los personajes han aprendido la lección de que la solidaridad con seres ajenos a nuestro grupo, y la debilidad a la hora de enfrentarlos, nunca es recompensada positivamente, como hasta entonces había sucedido en el maisntream hollywoodiense. Un capítulo de la cuarta temporada (2013-2014) comienza con la negación de auxilio de los protagonistas (Carl y Michonne si no recuerdo mal), que observan impasibles desde el coche en que viajan las llamadas de auxilio de un joven mochilero que camina junto a la carretera. En vez de ayudarle le dirigen miradas exentas de emoción, dando aparentemente su vida por perdida ya que sus condiciones personales no parecen las mejores. Y en efecto, al final del capítulo los protagonistas recorren el camino inverso y ven sobre la carretera lo que queda del joven, algunos restos de su cuerpo devorado por los zombis y la mochila. De nuevo, una situación impensable en el moralista mainstream del siglo XX convertida en habitual, y hasta irrelevante, en el siglo XXI.

En la película The Day (Doug Aarniokoski, 2011) se traspasa otra frontera en el terreno moral: un niño y una niña de unos ocho a diez años, los hijos del líder de una tribu caníbal, son representados como asesinos implacables, aleccionados por su padre en el arte de matar. Decimos que es una frontera porque la representación de niños asesinos (fuera del género fantasioso, en el que sí son frecuentes los chicos y chicas endemoniadas), es un terreno inexplorado para Hollywood, ignoro si por cordura o por censura. El primer caso que conozco es Rules of Engagement (William Friedkin, 2000), precisamente del director que retrató la posesión diabólica de una niña preadolescente en The Exorcist, 1973. En Rules of Engagement, una película sobre un juicio a un coronel y las diferentes versiones de los hechos que dieron lugar al mismo, podremos ver a una niña terrorista de unos siete u ocho años disparando contra soldados estadounidenses en la embajada de Yemen. Si en la versión de uno de los testigos la población civil ejercía su derecho a la protesta pacífica, en la versión real todos estaban armados y disparaban contra los soldados, incluida la niña.

1 Encontramos otros ejemplos de solidaridad «contraproducente o contraindicada» dentro y fuera del subgénero postapocalíptico, en series Gotham, 2014-..., iZombie, 2015-..., o Fear The Walking Dead, (2015-...). 
En The Day no hay versiones alternativas que suavicen la situación, el retrato de una niña terrorista y asesina. De hecho, asistimos a una escena en la cual el padre enseña a sus hijos cómo atacar y matar a los héroes. La representación de los niños asesinos es considerada tan relevante como para establecer un debate sobre ella. Una mujer del grupo protagonista, asediado en una casa por la tribu que pretende devorarles, mata sin querer al niño caníbal y se derrumba moral y emocionalmente, aunque sus compañeros intentar convencerla de que era lo correcto. Poco después traicionará y abandonará a la protagonista de la película, una caníbal arrepentida, y es asesinada por la niña, que se ceba en su miedo apareciendo y desapareciendo súbitamente y asestándole continuas puñaladas. El final de la película nos muestra la conclusión del debate: la niña, única superviviente de la tribu caníbal, intenta convencer a la única superviviente del heroico grupo para que la lleve con ella. Los espectadores sabemos que es una trampa, y que su actitud de niña indefensa y aturdida es sólo una pose, pues esconde su minúsculo puñal. Cuando la protagonista le da la espalda, la niña se abalanza sobre ella. Pero la otra estaba prevenida, no había creído ni una palabra, así que se gira a gran velocidad y rebana la cabeza de la niña con su espada. Fin de la película. Moraleja: el mal está presente en todos los seres, incluidos los aparentemente inocentes. En la película, mostrar debilidad ante ellos es la perdición (te acaban matando si bajas la guardia). En la realidad, tampoco merecen nuestra solidaridad porque están hechos de la misma pasta que sus padres, nuestros rivales por los recursos, nuestros enemigos.

La última película que citaré es World War Z (Marc Forster, 2013), protagonizada por Brad Pitt en el papel de Gerry Lane, un antiguo trabajador de las Naciones Unidas que viaja por un mundo devastado por la plaga zombi para encontrar la cura. Si en los ejemplos citados hasta ahora se escenifica la necesidad del abandono de la vieja moral a nivel individual, en World War Z se representa la necesidad de dar por perdidas sociedades enteras. La política de la supervivencia y la moral de la supervivencia son las dos caras de la misma moneda, y a ellas debemos adecuarnos. Las partes desechables de la humanidad son encarnadas principalmente por Mexico, Palestina, y los sectores no productivos del primer mundo. Los habitantes de los países mencionados, y los del tercer mundo en general, son asociados con zombis que ponen en peligro nuestro estilo de vida occidental de clase media y alto nivel de consumo. La solidaridad es de nuevo castigada con la muerte, en este caso no de una persona concreta, sino de un país entero, Israel.

La solidaridad entre sociedades o diferentes grupos sociales no es la única tendencia moral que la película pretende neutralizar, describiéndola como mortalmente peligrosa. Dentro del mismo grupo social es un asunto meridiano que las personas que no cumplan una función no tienen cabida en el reducto de la sociedad estadounidense que sobrevive en los barcos de la Armada. «Todos cumplen un propósito, no hay espacio aquí para los que no son esenciales», se advierte a Gerry Lane, que será expulsado del barco junto con su familia si no acepta el encargo de localizar la cepa del virus. Y en efecto, cuando se pierde la comunicación y se le da por muerto, la familia es expulsada.

El mensaje vuelve a ser muy claro, como un aviso a navegantes: las personas que no sean productivas de alguna forma para la sociedad, serán abandonadas a su suerte. No es lo bondadoso, pero sí es lo correcto en la situación de emergencia, y tendremos que acostumbrarnos a verlo. ¿La justificación? En el barco, en la cola para recibir la comida, metáfora sobre la escasez de recursos en el planeta, la hija de Lane le comenta a la madre que el agua 
sabe rara. Un soldado que escucha el comentario se vuelve y contesta hiriente: «es verdad, no se filtra bien porque hay demasiada gente en este barco». Cada vez hay menos recursos, y si queremos mantener nuestro nivel de vida, es necesario soltar lastre.

La nueva ética del postapocalipsis corporativista encuentra sin embargo una frontera básica que no se ha de cruzar, a riesgo de perder la conciencia de la propia bondad: «We don't eat people.» Esto es lo que le queda al padre de The Road para demostrarle a su preocupado hijo que ellos son los buenos. No comemos personas. La predación e ingerimiento literal de semejantes queda reservada a los enemigos de nuestra pequeña sociedad grupal, para los inhumanos, para las bestias.

Nosotros, por mucha hambre que pasemos, no comemos personas. Podemos suspender la moral, podemos cerrar nuestros ojos ante la barbarie que nos rodea, provocada por las políticas predatorias y caníbales de nuestros dirigentes del primer mundo, que devoran la energía contenida en los cuerpos del resto en pos de una insensata acumulación de dividendos. Nosotros, los beneficiados momentáneamente por el sistema caníbal, que quizás nos dejemos manipular y sostengamos en los decenios que llegan la ética de la supervivencia que se nos propone, no comemos personas. A esto queda reducida la solidaridad en la realista distopía corporativista cuyas representaciones cinematográficas más acabadas se encuentran en la narrativa postapocalíptica. Nosotros somos los buenos no porque no seamos malos, si no porque los otros son peores, nos cuentan desde las instancias de poder.

\section{Bibliografía citada}

Klein, N. (2009): La doctrina del Shock. El auge del capitalismo del desastre, Barcelona, Paidós.

Matheson, R. (2007): I Am Legend, Nueva York, Tor.

Morgan, R. (2006): Leyes de mercado, Barcelona, Gigamesh.

Rodríguez de Austria, A. M. (2015): «El código de producción de Hollywood (1930-1966): censura, marcos (frames) y hegemonía.» ZER, Vol 20, No 39, 2015.

Ross, D. (2009): The Right and the Good, Oxford, Oxford University Press. 
